\title{
Determinants of $\mathrm{CO}_{2}$ emissions generated by air travel vary across reasons for the trip
}

\author{
Martin Thomas Falk ${ }^{1}$ (D) Eva Hagsten ${ }^{2}$ (D) \\ Received: 10 July 2020 / Accepted: 23 December 2020 / Published online: 12 January 2021 \\ (C) The Author(s) 2021
}

\begin{abstract}
This study estimates factors of importance for the carbon dioxide equivalent $\left(\mathrm{CO}_{2} \mathrm{e}\right)$ emissions generated by travellers flying for different reasons based on representative Austrian micro data for the period 2014-2016. The annual average number of flights taken by adults vary between 0.1 (visiting friends) and 0.8 (going on holiday), and the amount ${ }^{2} \mathrm{CO}_{2} \mathrm{e}$ emissions generated by each return flight is approximately $1100 \mathrm{~kg}$. This leads to a total of 6 million tonnes $\mathrm{CO}_{2} \mathrm{e}$ emissions per year. Results of the Pseudo Poisson Maximum Likelihood estimations reveal that the amount of $\mathrm{CO}_{2} \mathrm{e}$ emissions created is related to socio-demographic, locational and seasonal factors, although mainly for the largest group of travellers: the holiday makers. In this group, individuals with university degrees, young persons (16-24 years) and capital city residents generate the largest amounts of emissions, as opposed to persons with children and large households. Residents of the capital region each quarter cause $64 \mathrm{~kg}$ more $\mathrm{CO}_{2} \mathrm{e}$ emissions than inhabitants of rural areas, persons with university degrees create $74 \mathrm{~kg}$ larger emissions than those without degrees and young adults instigate $90 \mathrm{~kg}$ more emissions than middle-aged persons. $\mathrm{CO}_{2} \mathrm{e}$ emissions of holiday flights are highest in the first quarter of the year. The importance of education is also pronounced for $\mathrm{CO}_{2} \mathrm{e}$ emissions related to business travel, as is gender.
\end{abstract}

Keywords Air travel $\mathrm{CO}_{2}$ emissions $\cdot$ Tourist air travel $\cdot$ Business air travel $\cdot$ Count data models

\section{Introduction}

Services related to tourism, including air transportation, are increasingly questioned because of their presumptive negative impact on global carbon emissions. Air travel is considered to be the most environmentally damaging form of transportation with respect to climate change (Gössling and Upham 2009; Gössling and Humpe 2020) and

Responsible editor: Philippe Garrigues

Martin Thomas Falk

martin.falk@usn.no

Eva Hagsten

evamarie@hi.is

1 School of Business, Department of Business and IT, University of South-Eastern Norway, Campus Bø; Gullbringvegen 36, 3800 Bø, Norway

2 School of Social Sciences, University of Iceland, Reykjavík, Iceland emissions from aviation are more harmful than those from ground traffic (Lee et al. 2009). Findings based on research undertaken before the Covid-19 pandemic grounded most aircraft fleets in early 2020 point to the fact that a small group of individuals contributes to a large amount of the $\mathrm{Co}_{2}$ emissions (Gössling et al. 2009; Brand and Preston 2010; Gössling and Humpe 2020). Despite this, the characteristics of those individuals who generate the largest amount of flight-related emissions by reason for travel (holiday, visiting friends and relatives or business) are presently unknown.

The aim of this study is to gain more insights into aspects of importance for the $\mathrm{CO}_{2}$ emissions generated by air travellers with different reasons for their trips. Socio-demographic, locational and seasonal factors are employed to explain the amount of emissions at the individual level. The analysis uses a representative micro data set of 17,400 observations on Austrian residents that travel at least once per quarter for reasons of businesses, holidaying or visiting friends and relatives during the period 2014-2016. The Pseudo Poisson Maximum Likelihood estimator (PPML) is employed to estimate the relationships. 
Until 2020, long-haul air travel is the fastest growing segment of passenger mobility (Airbus 2018) and ICAO (2009) estimates a 300\% increase in emissions from air travel by 2050 . Total aviation emissions are considered to account for $20 \%$ of the global tourism carbon footprints (Lenzen et al. 2018), while aviation itself represents between 2.0 and $2.5 \%$ of total annual $\mathrm{CO}_{2}$ emissions (Lee et al. 2009, Graver, Zhang and Rutherford, 2019). Current discussions encompass not only the sustainability of frequent flying, primarily by business travellers (Young et al. 2014), but increasingly also "unnecessary" leisure and holiday travel (Becken 2002; Holden and Norland 2005; Graham and Metz 2017).

With the deregulation of the European and other aviation markets and the subsequent emergence of low-cost airlines, the share of holiday air travel in total number of passengers is increasing (O'Connell and Williams 2005; Tsui 2017; Álvarez-Díaz et al. 2019). Recently, new groups of environmental activists have appeared that emphasise the emissions caused by flying, introducing the Swedish term "flygskam" (flight shame) (Gössling et al. 2019; Gössling 2019; Gössling et al. 2020). ${ }^{1}$ These groups advocate alternative transportation modes such as train, even if the travel time is ten or twenty folded.

Air travel for purposes of business, migration and education as well as to visit friends and relatives may be difficult to avoid. Many firms, institutions and organisations are active on the international arena and longdistance relationships are not uncommon. There are also national or European parliamentarians, for instance, who are expected to have a close relationship with their constituencies even if the distances are far. Yet, holiday travel by air could be prevented to a certain extent, as environmentally friendly means of transportation are available for short- or medium-long distances. In general, the distribution of emissions caused by air transportation is highly uneven, with few people accounting for the largest proportion (Brand and Preston 2010).

Hardly any studies examine the link between aviation emissions and socio-demographic characteristics. An exception is Bruderer Enzler (2017), who uses a two-part model to investigate the determinants of air traffic emissions based on the Swiss environmental survey. Other studies focus on greenhouse gas emissions of all individual travellers, independent of characteristics (e.g. Brand and Preston 2010), long-distance travellers (Reichert et al. 2016) or travel emissions generated by the urban population (Czepkiewicz et al. 2018a, 2018b; Czepkiewicz et al. 2019).

\footnotetext{
${ }^{1}$ See for instance article in Time Magazine, May 16, 2019 "Now I Am Speaking to the Whole World.' How Teen Climate Activist Greta Thunberg Got Everyone to Listen" (https://time.com/collection-post/5584902/gretathunberg-next-generation-leaders/).
}

Another strand of the literature examines flying behaviour in general, independently of the amount of $\mathrm{CO}_{2}$ emissions caused. Examples of this include the behaviour of (a) the urban population in Iceland (Czepkiewicz et al. 2020), (b) international celebrities (Gössling 2019), (c) German holiday makers (Gössling et al. 2017) and (d) Swiss inhabitants and distances of their flights (Schubert et al. 2020). Dargay and Clark (2012) explore the determinants of travel for five different purposes (business, commuting, leisure, holidays and visits from friends and relatives), but without accounting for the emissions generated.

This study contributes results on a far more detailed level of air travellers and their carbon footprints than hitherto available based on a regularly re-occurring representative official survey. In addition, the analysis takes into account how the importance of socio-demographic, locational and seasonal factors varies across reasons for travel.

The paper is structured as follows: the "Conceptual background" section introduces the theoretical background and provides the main hypothesis, the "Empirical model" section presents the empirical approach while the "Data and descriptive statistics" section describes the dataset. The empirical results are revealed in the "Empirical results" section and the "Conclusion" section concludes.

\section{Conceptual background}

Few studies investigate the characteristics of the group of air travellers that generate the largest amounts of $\mathrm{CO}_{2}$ emissions. A review of 27 studies examining the behaviour of long-haul travellers only encompasses three studies relating to $\mathrm{CO}_{2}$ emissions (Czepkiewicz et al. 2018a). Graham and Metz (2017) propose a distinction between "discretionary" leisure travel (including holiday travel) and "non-discretionary" business travel where air travels motivated by visiting friends and relatives are in principle voluntary but often indispensable.

Socio-demographic characteristics as well as location may have an important influence on $\mathrm{CO}_{2}$ emissions of individuals and households in general (Qu et al. 2016; Bülbül et al. 2020). Analyses of $\mathrm{CO}_{2}$ emissions associated with air travel reveal that socio-demographic characteristics and location of individuals are equally important (Reichert et al. 2016; Bruderer Enzler 2017; Czepkiewicz et al. 2018a; Czepkiewicz et al. 2018a, 2018b). Common features considered in these cases are age, gender, household type, education, occupation and income. Persons living in urban regions with airports close by are not only more likely to go by plane but are also using this opportunity regularly and subsequently generate more $\mathrm{CO}_{2}$ emissions (Czepkiewicz et al. 2018a). One reason behind this pattern is the so-called escape travel or compensation hypothesis (Heinonen et al. 
2013; Reichert et al. 2016) postulating that high urban density limits the quality of life and thus creates demand for frequent weekend trips and other short breaks. Czepkiewicz et al. (2018a) mention that the positive relationship between urban density and long-distance travel behaviour is still significant when demographic and socioeconomic variables are controlled for.

Research that explicitly models the $\mathrm{CO}_{2}$ emissions demonstrates that greenhouse gas emissions by urban residents are five times higher than those generated by individuals living in rural areas (Heinonen et al. 2013). Additionally, there are a number of studies that point to the importance of education and income as drivers of air travel emissions (e.g. Bruderer Enzler 2017). Likewise, the phase of life appears to be important for the emissions created. Based on the Swiss environmental survey, Bruderer Enzler (2017) finds that household characteristics and family size are important, while the role of gender is less obvious. Brand and Preston (2010), for instance, suggest that gender is not significantly related to overall emissions from private, non-business travel while Brand and Boardman (2008) show that single-person households produce the highest average travel emissions per person, mainly caused by air travel.

Unfortunately, recent literature is difficult to compare because of variations in sample sizes, definitions and calculations of $\mathrm{CO}_{2}$ emissions from air travel (total air travel emissions or by purpose) as well as estimation methods used (multivariate or bivariate). There are, however, a few common denominators indicating that socio-demographic factors are of importance, although possible differences between leisure (holiday and visiting friends or relatives) and business travellers are largely neglected. Influenced by the determinants highlighted in the literature, and the gaps revealed, the emissions generated are analysed for the travel purpose (holiday, business, visiting friends or relatives) together with socio-demographic, location and seasonal characteristics based on a representative sample of trips and travellers. Data available on destination country makes it possible to calculate the amount of emissions as carbon dioxide equivalents $\left(\mathrm{CO}_{2} \mathrm{e}\right)$ caused by the flights. This leads to the main hypothesis $(\mathrm{H} 1)$ :

H1: The determinants of $\mathrm{CO}_{2}$ e emissions generated by air travel vary across reasons for the trip. Implicitly, the hypothesis rests on the assumption that there is a relationship between emissions generated and socio-demographic, locational and seasonal factors.

\section{Empirical model}

There are numerous studies on the choice to travel by air (Czepkiewicz et al. 2018a). This study follows Bruderer Enzler (2017) and Reichert et al. (2016), who model the amount of air travel-related $\mathrm{CO}_{2} \mathrm{e}$ emissions, $\mathrm{CO} 2 e_{i t p}$, as a function of several socio-demographic factors including location, departure quarter and departure year:

$$
\begin{aligned}
& C O 2 e_{i t p}=\beta_{0 p}+\sum_{A=1}^{5} \beta_{j p A} A G E C A T_{i t}^{A}+\sum_{E=1}^{2} \beta_{j p E} E D U_{i t}^{E}+\beta_{j p W} W O M E N_{i t} \\
& +\beta_{j p C} \text { CHILDREN } N_{i t}+\sum_{S=1}^{3} \beta_{j p L} L_{A B B O U R T A T U S}^{L}+\sum_{H=1}^{5} \beta_{j p H} H_{H S I Z E_{i t}^{H}} \\
& +\sum_{F=1}^{8} \beta_{j p F} F E D S T A T E_{i t}^{F}+\sum_{Y=1}^{2} \beta_{j p Y} Y E A R_{i t}^{Y}+\sum_{Q=1}^{3} \beta_{j p Q} Q U A R T E R_{i t}^{Q}+\varepsilon_{i p t},
\end{aligned}
$$

where $i$ is the individual, $t$ denotes quarterly data (2014:1 to 2016:4) and $p$ is reason for travel (holiday, visit friends and relatives or business). The explanatory variables encompass AGECAT denoting age class, EDU reflecting the level of education with no degree as the reference category and WOMEN if the traveller is female. CHILDREN is a dummy variable for travelling at least once with children, HHSIZE is a set of dummy variables measuring the household size with one reflecting the reference category and LABOURSTATUS is a group of dummy variables for the labour market position (employed, unemployed, student or retired, with unemployed as reference category).
Variable FEDSTATE relates to the region where the traveller resides with the province Lower Austria as the reference category. Macroeconomic factors such as price effects and fluctuations of the business cycle are captured by annual year dummy variables YEAR, QUARTER controls for calendar effects within a single year with the first quarter (January to March) as the reference category and $\varepsilon_{i p t}$ is the error term.

The Pseudo Poisson Maximum Likelihood estimator can be used to assess the determinants of the $\mathrm{CO}_{2} \mathrm{e}$ emissions generated by different groups of travellers. Santos Silva and Tenreyro (2006) argue that this estimator is suitable for 
dependent variables that contain a large proportion of zero values as in this case, where $82 \%$ of the leisure travellers and $95 \%$ of the business travellers did not fly at all in a given quarter and thus generate no $\mathrm{CO}_{2} \mathrm{e}$ emissions. Another advantage is that the PPML estimator is consistent in the presence of heteroscedasticity. The $\mathrm{CO}_{2} \mathrm{e}$ emission equation can be written in its exponential form (subscript $t$ omitted):

$\mathrm{CO}_{2} e_{i}=\exp \left(X_{i} \beta\right)+\epsilon_{i}$,

where $X$ is the vector of explanatory variables mentioned above (all in form of dummy variables) and $\beta$ contains the parameters to be estimated.

\section{Data and descriptive statistics}

Data for this analysis originate from the official Austrian travel survey (Statistics Austria 2017). This is a quarterly representative survey on holiday and business travels with at least one overnight stay, undertaken by persons living in Austria aged 15 years or older. The survey is stratified by federal state, age and gender. Each quarter, around 3500 randomly selected persons are interviewed by telephone. Participation in the survey is voluntary. The dataset encompasses information on actual domestic as well as international (outbound) trips by destination and purpose, length of stay, accommodation type, departure month, transportation mode and expenditures. A wide range of socio-demographic factors accompany the data such as educational attainment, gender, age class, labour market status, travel company size and federal state where the traveller resides. Although information is available from 2012 onwards, methodological changes of the travel survey restrict the estimation sample to the period 2014-2016.

Data on destination country makes it possible to calculate the amount of $\mathrm{CO}_{2}$ emissions (expressed in carbon dioxide equivalents) caused by the flights. The largest destination airport in each country is used for this exercise. There are two different emission calculators available (https://co2. myclimate.org/en/flight_calculators/new and https://www. icao.int/environmental-protection/Carbonoffset/Pages/ default.aspx) (Table 4, Appendix) although the one from the ICAO has a limited coverage of airports and is thus not used here. The myclimate flight calculator determines the amount of $\mathrm{CO}_{2}$ emissions that an aircraft generates per passenger for a given flight route using the real distance. Nitrogen compounds and aerosols are also taken into account and converted into $\mathrm{CO}_{2}$. Business flights are associated with $30 \%$ more $\mathrm{CO}_{2}$ emissions for short- and medium-haul flights. Since information is not available on the number of flights in business class, the calculation method for economy flights is used for all flights as in Reichert et al. (2018). $\mathrm{CO}_{2} \mathrm{e}$ emissions generated by each quarterly trip are aggregated to the individual level.
Table 1 Amount of $\mathrm{CO}_{2} \mathrm{e}$ emissions generated by different groups of air travellers $(\mathrm{kg})$

\begin{tabular}{llcr}
\hline & Holiday & Visit friends or relatives & Business \\
\hline & Total & \\
2014 & $1,040,046$ & 131,970 & 382,938 \\
2015 & $1,075,104$ & 141,004 & 327,740 \\
2016 & $1,086,714$ & 206,876 & 340,358 \\
& Upper one percentile of emitters \\
2014 & 199,718 & 89,174 & 250,866 \\
2015 & 226,692 & 101,876 & 208,306 \\
2016 & 218,786 & 155,320 & 214,724 \\
& Contribution of the upper one percentile, per cent \\
2014 & 19.2 & 67.6 & 65.5 \\
2015 & 21.1 & 72.3 & 63.6 \\
2016 & 20.1 & 75.1 & 63.1 \\
\hline
\end{tabular}

Source: Austrian travel survey and https://co2.myclimate.org/en/flight_ calculators/new

Although Baumeister (2017) concludes that almost no single flight generates similar emissions to another, depending on the number of stops and the vintage of the plane, a more detailed calculation of the emissions cannot be made here because information about the travel itself is not available.

Descriptive statistics also reveal that $1 \%$ of the holiday travellers and $1 \%$ of the business air travellers account for one-fifth and almost two-thirds of $\mathrm{CO}_{2} \mathrm{e}$ emissions during the sample period in their respective groups (Table 1). Emissions generated by flights to friends and relatives are negligible in this context.

Based on the average number of holiday flights per person and year (0.8), the amount of $\mathrm{CO}_{2} \mathrm{e}$ emissions can be calculated. The emissions are then scaled up to the total adult population of 7.6 million in Austria, of which $60 \%$ goes on holiday (European Comission 2016). With the corresponding $\mathrm{CO}_{2} \mathrm{e}$ emissions of $1100 \mathrm{~kg}$ per person and flight, this results in a total amount of $\mathrm{CO}_{2} \mathrm{e}$ emission per year of approximately 6 million tonnes from air travel (and 4.0 million tonnes from the holiday travel). Based on a representative travel survey for Sweden, Åkerman (2012) calculates 4.2 million tonnes of $\mathrm{CO}_{2}$ equivalent emissions from international air travel for the period 2015-2016 (1 year, including all types of flights). In addition, descriptive statistics show that the $\mathrm{CO}_{2} \mathrm{e}$ emissions per person with at least one flight vary markedly over quarters, where the highest appears in the first quarter, reflecting the longer flight distances during this time of year (Table 2).

The $\mathrm{CO}_{2} \mathrm{e}$ emissions generated by each holiday traveller (with at least one flight per quarter) are larger for highly skilled individuals (tertiary degrees), those living in the capital city of Vienna and for young people (Fig. 1). 
Table 2 Average number of flights per quarter and $\mathrm{CO}_{2} \mathrm{e}$ emissions per flight in 2014-2016

\begin{tabular}{|c|c|c|c|}
\hline & \multicolumn{3}{|c|}{ Number of flights } \\
\hline & Holiday & Visit friends or relatives & Business \\
\hline 2014 Q1 & 0.16 & 0.03 & 0.09 \\
\hline 2014 Q2 & 0.21 & 0.03 & 0.09 \\
\hline 2014 Q3 & 0.27 & 0.02 & 0.06 \\
\hline 2014 Q4 & 0.17 & 0.03 & 0.09 \\
\hline 2015 Q1 & 0.20 & 0.04 & 0.08 \\
\hline 2015 Q2 & 0.21 & 0.03 & 0.09 \\
\hline 2015 Q3 & 0.23 & 0.02 & 0.05 \\
\hline 2015 Q4 & 0.14 & 0.04 & 0.08 \\
\hline 2016 Q1 & 0.14 & 0.03 & 0.07 \\
\hline 2016 Q2 & 0.21 & 0.03 & 0.09 \\
\hline 2016 Q3 & 0.23 & 0.03 & 0.05 \\
\hline 2016 Q4 & 0.15 & 0.05 & 0.08 \\
\hline Sum 2014 Q1-Q4 & 0.81 & 0.12 & 0.34 \\
\hline Sum 2015 Q1-Q4 & 0.78 & 0.12 & 0.30 \\
\hline \multirow[t]{3}{*}{ Sum 2016 Q1-Q4 } & 0.74 & 0.15 & 0.28 \\
\hline & \multicolumn{3}{|c|}{$\mathrm{CO}_{2} \mathrm{e}$ emissions per person in $\mathrm{kg}$ (persons with at least one flight in any of the categories) } \\
\hline & Holiday & Visit friends or relatives & Business \\
\hline 2014 Q1 & 1534 & 831 & 1251 \\
\hline 2014 Q2 & 820 & 851 & 1228 \\
\hline 2014 Q3 & 817 & 758 & 1276 \\
\hline 2014 Q4 & 1091 & 991 & 1241 \\
\hline 2015 Q1 & 1364 & 890 & 1205 \\
\hline 2015 Q2 & 914 & 816 & 1096 \\
\hline 2015 Q3 & 835 & 1007 & 992 \\
\hline 2015 Q4 & 1236 & 1111 & 1275 \\
\hline 2016 Q1 & 1670 & 1059 & 1233 \\
\hline 2016 Q2 & 742 & 1105 & 859 \\
\hline 2016 Q3 & 876 & 876 & 1185 \\
\hline 2016 Q4 & 1257 & 1027 & 1654 \\
\hline Mean 2014 Q1-Q4 & 1065 & 858 & 1249 \\
\hline Mean 2015 Q1-Q4 & 1087 & 956 & 1142 \\
\hline Mean 2016 Q1-Q4 & 1136 & 1017 & 1233 \\
\hline
\end{tabular}

Source: Austrian travel survey. Average $\mathrm{Co} 2$ emissions per flight in $\mathrm{kg}$ are calculated based on a return flight using https://co2.myclimate.org/en/flight_calculators/new
Among business air travellers, those with higher education account for the majority of emissions (Table 5, Appendix). $\mathrm{CO}_{2} \mathrm{e}$ emissions created are higher in the older age classes of holiday travellers.

\section{Empirical results}

The Pseudo Poisson Maximum Likelihood estimations show that the amount of $\mathrm{COe}_{2}$ emissions generated by air travellers residing in Austria relates to socio-demographic, locational and seasonal factors, although mainly for the largest group of travellers: the holiday makers (Table 3 ). In this group, young adults, those with tertiary degrees, residents of the capital city and men leave larger traces of $\mathrm{CO}_{2} \mathrm{e}$ emissions. Individuals travelling with children and those in large household generate far less emissions. There is also a strong seasonal pattern, where the lowest $\mathrm{CO}_{2} \mathrm{e}$ emissions can be observed for the second and fourth quarters of the year.

The labour market status is not related to the amount of $\mathrm{CO}_{2} \mathrm{e}$ emissions created by holiday travellers. $\mathrm{CO}_{2} \mathrm{e}$ emissions resulting from flights to friends and relatives show that the main aspects of importance are the educational level and the capital region, while the remaining factors are of less or no importance. Since the capitals attract highly educated individuals, it can be expected that there is also a larger amount of residents with families elsewhere. Emissions related to 

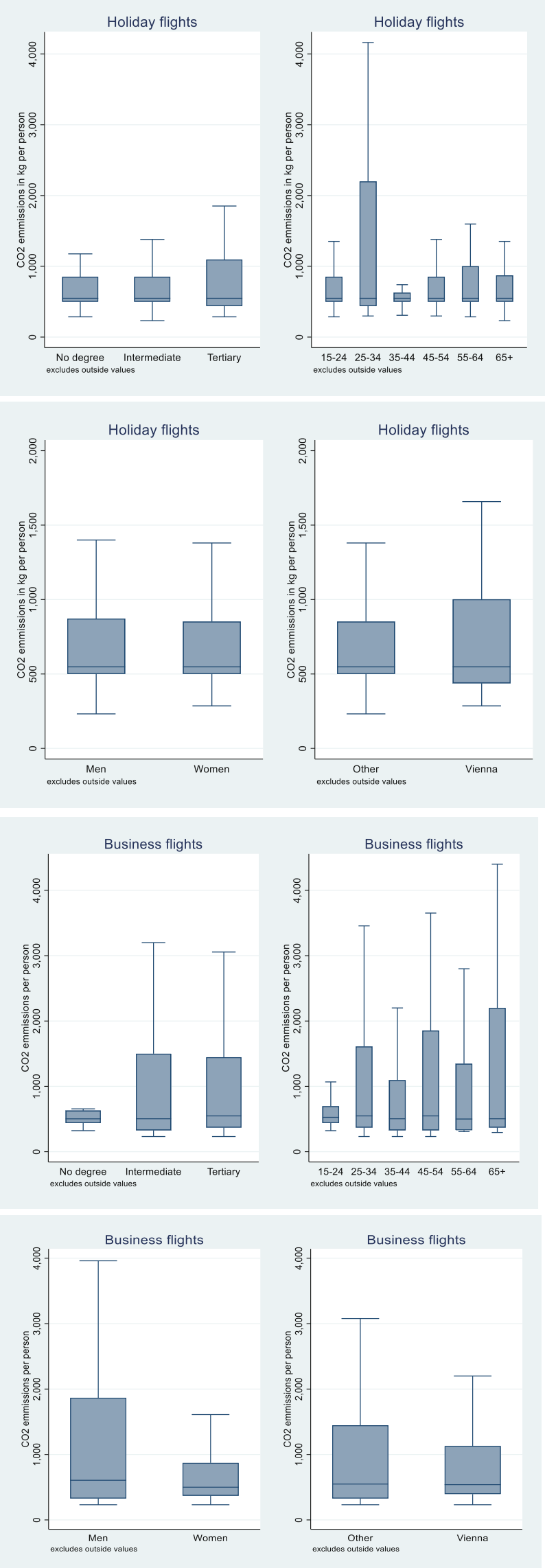

Fig. 1 Box plots of individual $\mathrm{CO}_{2}$ e emissions per group of travellers. Source: Austrian travel survey

business travels are crucially related to the educational level, labour market status, gender and location. Season is far less important, but there is a reduction in the summer quarter (July to September).

The marginal effects $(\mathrm{dy} / \mathrm{dx})$ of the PPML estimations directly indicate the strength of the associations and reveal that young holiday travellers aged $15-24$ years produce the highest amount of $\mathrm{CO}_{2} \mathrm{e}$ emissions per quarter compared to the reference category 35-44 years (90 kg more). Persons with higher education generate $74 \mathrm{~kg}$ and $76 \mathrm{~kg}$ more emissions for holiday and business travels, respectively, than those without degrees. Inhabitants of the capital region are responsible for an addition of $64 \mathrm{~kg}$ emissions for holiday flights than people living in the rural provinces. Strong associations can also be observed for holiday travellers with children $(-66 \mathrm{~kg})$ and persons living in large households $(-52 \mathrm{~kg}$ and $-72 \mathrm{~kg}$ in households with 5 and 6 or more persons, respectively). Emissions from holiday flights are lowest in the spring and autumn months ( $-65 \mathrm{~kg}$ each). In terms of emissions from business flights, women relate to a reduced amount of emissions with $68 \mathrm{~kg}$. Overall, the results mean that the hypothesis formulated cannot be rejected.

In general, the results do not deviate from the recent but fragmented literature, although the analysis performed here goes beyond earlier research both with respect to the large representative dataset and the calculation and modelling of flight-related $\mathrm{CO}_{2} \mathrm{e}$ emissions by travel purpose. Estimates based on total emissions mask the heterogeneity of the air travel behaviour among different groups, where emissions created by those travelling to visit friends and relatives are less related to sociodemographic factor than for the holiday makers. This approach also allows a ranking of the importance of the explanatory variables, where young persons, those with higher degrees or residents of the capital city generate more $\mathrm{CO}_{2} \mathrm{e}$ emissions for their holiday flights and highly educated persons and men for those of business flights.

Several robustness checks have been conducted. First, other $\mathrm{CO}_{2} \mathrm{e}$ calculation methods are used. The findings are not sensitive to the choice of the $\mathrm{CO}_{2} \mathrm{e}$ calculator (results are available upon request). Second, the central variables age, education and place of residence are interacted to investigate possible moderating effects. The results for holiday flights show that persons with tertiary education living in the capital city cause the highest amount of emissions (unreported results are available upon request).

Given that the emissions generated clearly vary across kind of travellers, with the holiday makers being 
Table 3 PPML estimations of the amount of $\mathrm{CO}_{2} \mathrm{e}$ emissions generated by air travel 2014-2016

(i)

\begin{tabular}{|c|c|c|c|c|c|c|c|c|c|}
\hline & Holiday & (i) & & Visit friends & $\begin{array}{l}\text { (ii) } \\
\text { relati }\end{array}$ & & Business & (iii) & \\
\hline & $\mathrm{dy} / \mathrm{dx}$ & & z-stat & $\mathrm{dy} / \mathrm{dx}$ & & z-stat & $\mathrm{dy} / \mathrm{dx}$ & & z-stat \\
\hline Age 15-24 (ref. cat. 35-44) & 89.66 & $* * *$ & 4.05 & 14.45 & $*$ & 1.97 & 15.81 & & 0.95 \\
\hline Age $25-34$ & 55.53 & $* * *$ & 3.05 & 5.71 & & 0.85 & 6.37 & & 0.65 \\
\hline Age $45-54$ & 48.31 & $* * *$ & 2.97 & -5.38 & & -0.78 & 4.02 & & 0.43 \\
\hline Age 55-64 & 23.41 & & 1.25 & 2.46 & & 0.32 & -3.19 & & -0.26 \\
\hline Age $65+$ & 29.53 & & 1.22 & -5.21 & & -0.50 & -9.72 & & -0.47 \\
\hline Education medium (ref. low) & 22.23 & & 1.53 & -1.39 & & -0.21 & 5.87 & & 0.46 \\
\hline Education tertiary level & 74.00 & $* * *$ & 4.42 & 15.95 & $* *$ & 2.29 & 76.05 & $* * *$ & 5.57 \\
\hline Women & 19.91 & $* *$ & 2.24 & 6.45 & * & 1.72 & -68.50 & $* * *$ & -8.31 \\
\hline Travellers with children & -65.62 & $* * *$ & -4.43 & -4.48 & & -0.84 & & & \\
\hline Employed (ref. unemployed) & 7.80 & & 0.26 & 5.73 & & 0.56 & 52.00 & $* * *$ & 2.65 \\
\hline Student & 2.97 & & 0.09 & 19.01 & & 1.63 & 42.18 & $*$ & 1.89 \\
\hline Pensioners/out of labour force & -0.95 & & -0.03 & 18.26 & & 1.48 & -42.52 & $*$ & -1.65 \\
\hline Burgenland (ref. Lower Austria) & -22.74 & & -0.76 & 8.10 & & 0.50 & -35.96 & & -1.40 \\
\hline Vienna & 63.77 & $* * *$ & 4.79 & 24.37 & $* * *$ & 4.22 & 24.16 & $* *$ & 2.33 \\
\hline Carinthia & -61.06 & $* *$ & -2.49 & -6.42 & & -0.71 & -3.05 & & -0.17 \\
\hline Styria & -30.07 & $*$ & -1.80 & -10.73 & & -1.37 & -5.33 & & -0.46 \\
\hline Upper Austria & -25.74 & $*$ & -1.78 & -1.52 & & -0.20 & -11.76 & & -1.08 \\
\hline Salzburg & -3.42 & & -0.17 & 16.61 & $* *$ & 1.96 & -7.92 & & -0.46 \\
\hline Tyrol & -6.59 & & -0.34 & 10.92 & & 1.35 & -36.68 & $* *$ & -2.11 \\
\hline Vorarlberg & -0.48 & & -0.02 & 16.66 & $*$ & 1.90 & 31.69 & $* *$ & 2.10 \\
\hline Household size $=2($ ref. $=1)$ & 27.19 & $*$ & 1.85 & -11.66 & $* *$ & -2.12 & -19.64 & * & -1.82 \\
\hline Household size $=3$ & -17.92 & & -1.07 & -7.59 & & -1.25 & -25.27 & $* *$ & -2.29 \\
\hline Household size $=4$ & -41.45 & $* *$ & -2.30 & -14.00 & $* *$ & -2.03 & -22.74 & $* *$ & -2.05 \\
\hline Household size $=5$ & -52.28 & $* *$ & -2.30 & -14.68 & $*$ & -1.74 & -11.51 & & -0.95 \\
\hline Household size $=6$ & -71.55 & $* *$ & -2.47 & -2.30 & & -0.25 & -21.50 & & -1.00 \\
\hline Year 2015 (ref. year 2014) & -6.45 & & -0.60 & 0.07 & & 0.01 & -14.57 & $*$ & -1.82 \\
\hline Year 2016 & -14.75 & & -1.37 & 9.18 & $* *$ & 2.06 & -14.93 & * & -1.85 \\
\hline Quarter 2 (ref. quarter 1) & -65.25 & $* * *$ & -4.94 & -1.79 & & -0.34 & 2.19 & & 0.25 \\
\hline Quarter 3 & -30.81 & $* *$ & -2.56 & -7.74 & & -1.48 & -19.25 & $* *$ & -2.11 \\
\hline Quarter 4 & -65.40 & $* * *$ & -4.46 & 8.21 & & 1.55 & 8.59 & & 0.85 \\
\hline Number of observations & 17,374 & & & 17,374 & & & 17,374 & & \\
\hline Log pseudolikelihood & $-6,390,698$ & & & $-1,774,704$ & & & $-3,087,037$ & & \\
\hline
\end{tabular}

Notes: Asterisks $* * *, * *$ and $*$ denote significance at the 1,5 and $10 \%$ levels. dy/dx denotes the marginal effects. Estimated by the Poisson pseudomaximum likelihood estimator. Source: Austrian travel survey, Statistics Austria

responsible for the largest amount, possible policy interventions need to be customised. Literature suggests both voluntary initiatives and soft measures as well as hard actions (flight taxes, emissions taxes, carbon budget) to reduce the emissions of holiday flights (Becken 2007; Higham et al. 2016; Shaari et al. 2020), with hard measures being considered the most effective ones (Higham et al. 2016). Gössling et al. (2020) show that a two-thirds majority of survey respondents are in favour of marketbased measures that increase the cost of flying, policies that force airlines to reduce their emissions and legislation to abolish subsidies. Using a willingness-to-pay approach, Seetaram et al. (2018) demonstrate that travellers are willing to pay a higher departure tax for business class and long-haul travel. Another policy option is to replace shorthaul and domestic flights with train connections (Dällenbach 2020). According to Baumeister (2019), airplanes have no advantage over trains for distances under $400 \mathrm{~km}$ and the emission reduction potential would be particularly pronounced if the trains were run with renewable energy, shifting the responsibility of cleaner aviation to the supply side, where new technologies might 
be used as alternative solutions. Several airlines experiment with biofuels, for instance, with mixed evidence (Filimonau et al. 2018; Lu 2018; Efthymiou and Papatheodorou 2019). Other options suggested are electric airplanes, but this is not for the near future (Baumeister et al. 2020).

\section{Conclusions}

This study provides novel empirical evidence on aspects of importance for the carbon dioxide equivalent $\left(\mathrm{CO}_{2} \mathrm{e}\right)$ emissions caused by different groups of air travellers, based on a large representative dataset on travel behaviour by Austrian residents for the period 2014-2016. Poisson Pseudo-Maximum Likelihood estimations show that the amount of $\mathrm{CO}_{2} \mathrm{e}$ emissions generated by different groups of travellers depend on socio-demographic, locational and seasonal factors, although mainly so for the largest group of travellers: the holiday makers. Education, location of residence, age and season are aspects most relevant for $\mathrm{CO}_{2} \mathrm{e}$ emissions generated by this group of travellers while education and gender (men) are driving $\mathrm{CO}_{2} \mathrm{e}$ emissions by business travellers. Socio-demographic, locational and seasonal factors are of less or no importance for emissions related to visiting friends and relatives.

The results imply that presumptive policy measures to reduce travel by air need to be customised. Given that the largest amount of emissions are produced by persons with higher degrees, supposedly not sensitive to air fares, additional measures targeting the demand side such as flight taxes might not be effective in reducing emissions. Instead, focus might need to shift to the supply side and to new technologies.

Travel surveys from the national statistical office are commendable sources for the analysis of the $\mathrm{CO}_{2} \mathrm{e}$ emissions and are generally available in a large group of countries. Future studies should be based on comparable data for a larger group of countries.

Authors' contributions Martin Falk contributed 50\% to conceptualisation, literature review, data work, estimation, writing of the paper and revision. Eva Hagsten contributed 50\% to conceptualisation, literature review, data work, estimation, writing of the paper and revision.

Funding Open Access funding provided by University Of South-Eastern Norway.

Data availability Official data underlying the study can be ordered from Statistics Austria: http://www.statistik.at/web_de/services/mikrodaten fuer_forschung_und_lehre/datenangebot/standardisierte_datensaetze sds/index.html\#index 18

\section{Compliance with ethical standards}

Competing interests The authors declare that they have no conflicts of interest.

Ethical approval Not applicable.

Consent to participate Yes.

Consent to publish Yes. 


\section{Appendix}

Table 4 List of airports and $\mathrm{CO}_{2}$ equivalent emissions for return flights starting in Vienna

\begin{tabular}{|c|c|c|c|}
\hline \multirow[t]{2}{*}{ Country } & \multirow[t]{2}{*}{ Airport code } & \multicolumn{2}{|c|}{ Passenger $\mathrm{CO}_{2} \mathrm{e} / \mathrm{pax} /$ return $(\mathrm{KG})$} \\
\hline & & IACO & co2.myclimate.org \\
\hline Belgium & BRU & 220.6 & 408 \\
\hline Denmark & $\mathrm{CPH}$ & 197.0 & 396 \\
\hline Germany & FRA & 153.4 & 328 \\
\hline Finland & HEL & 281.2 & 550 \\
\hline France & $\mathrm{CDG}$ & 223.2 & 438 \\
\hline Greece & ATH & 247.4 & 502 \\
\hline United Kingdom & LHR & 251.0 & 500 \\
\hline Ireland & DUB & 310.0 & 628 \\
\hline Italy & FCO & 195.2 & 370 \\
\hline Luxembourg & LUX & 185.6 & 368 \\
\hline Netherlands & AMS & 209.0 & 416 \\
\hline Portugal & LIS & 392.2 & 832 \\
\hline Sweden & ARN & 289.4 & 504 \\
\hline Spain & PMI & 277.2 & 548 \\
\hline Iceland & $\mathrm{KEF}$ & 454.4 & 1020 \\
\hline Norway & OSL & 286.8 & 530 \\
\hline Switzerland & $\mathrm{ZRH}$ & 156.0 & 322 \\
\hline Baltic States (Estonia, Latvia, Lithuania) & RIX & 226.4 & 454 \\
\hline Croatia & SPU & 127.8 & 298 \\
\hline Malta & MLA & 263.4 & 526 \\
\hline Poland & WAW & 166.8 & 308 \\
\hline Romania & OTP & 200.4 & 382 \\
\hline Slovakia & $\mathrm{KSC}$ & n.a. & 256 \\
\hline Slovenia & LJU & n.a. & 232 \\
\hline Turkey & AYT & 301.0 & 628 \\
\hline Czech Republic & PRG & 107.8 & 236 \\
\hline Hungary & BUD & 89.0 & 220 \\
\hline Cyprus & LCA & 344.2 & 740 \\
\hline Bosnia and Herzegovina & SJJ & 144.4 & 294 \\
\hline Serbia & BEG & 122.0 & 286 \\
\hline Bulgaria & SOF & 201.0 & 376 \\
\hline Russia & VKO & 225.2 & 606 \\
\hline Rest of Europe & KBP & 221.2 & 446 \\
\hline Egypt & CAI & 372.6 & 852 \\
\hline Tunisia & TUN & 277.6 & 522 \\
\hline Rest of Africa & CPT & 1154.4 & 3000 \\
\hline USA & EWR & 780.8 & 2200 \\
\hline Canada & YYZ & 640.6 & 2200 \\
\hline Central and South America & GIG & n.a. & 3200 \\
\hline China & PEK & 659.6 & 2400 \\
\hline Rest of Asia & $\mathrm{BKK}$ & 741.4 & 2800 \\
\hline Australia, New Zealand and islands north-east of them in the Indian Ocean & SYD & n.a. & 5600 \\
\hline
\end{tabular}

Note: Carbon dioxide equivalent $\left(\mathrm{CO}_{2} \mathrm{e}\right)$ emissions refer to a return flight in the economy class

Source: https://co2.myclimate.org/en/flight_calculators/new and https://www.icao.int/environmental-protection/Carbonoffset/Pages/default.aspx 
Table $5 \quad \mathrm{CO}_{2}$ equivalent emissions by travel purpose and characteristics (2014-2016 per year on average)

\begin{tabular}{|c|c|c|c|}
\hline & Holiday & Visit friends and relatives & Business \\
\hline & \multicolumn{3}{|c|}{ Age class } \\
\hline Age $15-24$ & 149,987 & 31,637 & 42,061 \\
\hline Age $25-34$ & 147,586 & 23,303 & 69,492 \\
\hline Age $35-44$ & 114,967 & 19,657 & 71,300 \\
\hline Age $45-54$ & 232,321 & 21,889 & 93,893 \\
\hline Age 55-64 & 209,535 & 32,777 & 54,158 \\
\hline \multirow[t]{2}{*}{ Age $65+$} & 212,515 & 30,688 & 19,442 \\
\hline & \multicolumn{3}{|c|}{ Education } \\
\hline No degree & 140,241 & 25,908 & 28,804 \\
\hline Education medium (ref. low) & 588,495 & 73,613 & 125,485 \\
\hline \multirow[t]{2}{*}{ Education tertiary level (university) } & 334,310 & 60,220 & 194,853 \\
\hline & \multicolumn{3}{|c|}{ Children } \\
\hline Travellers without children & 953,099 & 139,703 & \\
\hline \multirow[t]{2}{*}{ Travellers with children } & 113,812 & 20,247 & \\
\hline & \multicolumn{3}{|c|}{ Gender } \\
\hline Men & 479,351 & 65,081 & 258,291 \\
\hline \multirow[t]{2}{*}{ Women } & 587,560 & 94,869 & 92,054 \\
\hline & \multicolumn{3}{|c|}{ Labour market status } \\
\hline Employed & 625,065 & 79,477 & 294,857 \\
\hline Unemployed & 7131 & 436 & 865 \\
\hline Student & 104,954 & 26,215 & 30,503 \\
\hline \multirow[t]{2}{*}{ Pensioners/out of labour force } & 306,820 & 50,603 & 19,589 \\
\hline & \multicolumn{3}{|c|}{ Federal state } \\
\hline Burgenland & 24,463 & 3921 & 4349 \\
\hline Lower Austria & 214,381 & 22,467 & 63,390 \\
\hline Vienna & 298,087 & 61,015 & 118,511 \\
\hline Carinthia & 43,749 & 5049 & 16,561 \\
\hline Styria & 117,865 & 10,399 & 37,699 \\
\hline Upper Austria & 176,731 & 20,924 & 52,360 \\
\hline Salzburg & 68,081 & 13,519 & 17,789 \\
\hline Tyrol & 76,701 & 13,214 & 13,829 \\
\hline \multirow[t]{2}{*}{ Vorarlberg } & 46,853 & 9441 & 25,857 \\
\hline & \multicolumn{3}{|c|}{ Household size } \\
\hline Household size $=1$ & 131,148 & 29,400 & 57,703 \\
\hline Household size $=2$ & 449,902 & 52,675 & 92,257 \\
\hline Household size $=3$ & 192,613 & 30,444 & 67,095 \\
\hline Household size $=4$ & 186,356 & 27,054 & 79,995 \\
\hline Household size $=5$ & 70,164 & 11,089 & 37,861 \\
\hline Household size $=6$ & 36,728 & 9287 & 15,434 \\
\hline
\end{tabular}

Note: $\mathrm{CO}_{2}$ equivalent emissions. Source: Austrian travel survey 
Open Access This article is licensed under a Creative Commons Attribution 4.0 International License, which permits use, sharing, adaptation, distribution and reproduction in any medium or format, as long as you give appropriate credit to the original author(s) and the source, provide a link to the Creative Commons licence, and indicate if changes were made. The images or other third party material in this article are included in the article's Creative Commons licence, unless indicated otherwise in a credit line to the material. If material is not included in the article's Creative Commons licence and your intended use is not permitted by statutory regulation or exceeds the permitted use, you will need to obtain permission directly from the copyright holder. To view a copy of this licence, visit http://creativecommons.org/licenses/by/4.0/.

\section{References}

Airbus (2018) Global market forecast, 2018-2037, Blagnac, France, https:// www.airbus.com/aircraft/market/global-market-forecast.html

Åkerman J (2012) Climate impact of international travel by Swedish residents. J Transp Geogr 25:87-93

Álvarez-Díaz M, González-Gómez M, Otero-Giráldez MS (2019) Low cost airlines and international tourism demand. The case of Porto's airport in the northwest of the Iberian Peninsula. Journal of Air Transport Management 79:101689

Baumeister S (2017) Each flight is different: carbon emissions of selected flights in three geographical markets. Transp Res Part D: Transp Environ 57:1-9

Baumeister S (2019) Replacing short-haul flights with land-based transportation modes to reduce greenhouse gas emissions: the case of Finland. J Clean Prod 225:262-269

Baumeister S, Leung A, Ryley T (2020) The emission reduction potentials of First Generation Electric Aircraft (FGEA) in Finland. J Transp Geogr 85:102730

Becken S (2002) Analysing international tourist flows to estimate energy use associated with air travel. J Sustain Tour 10(2):114-131

Becken S (2007) Tourists' perception of international air travel's impact on the global climate and potential climate change policies. J Sustain Tour 15(4):351-368

Brand C, Boardman B (2008) Taming of the few-the unequal distribution of greenhouse gas emissions from personal travel in the UK. Energy Policy 36:224-238

Brand C, Preston JM (2010) 60-20 emission'- the unequal distribution of greenhouse gas emissions from personal, non-business travel in the UK. Transp Policy 17:9-19

Bruderer Enzler HB (2017) Air travel for private purposes. An analysis of airport access, income and environmental concern in Switzerland. J Transp Geogr 61:1-8

Bülbül H, Büyükkeklik A, Topal A, Özoğlu B (2020) The relationship between environmental awareness, environmental behaviors, and carbon footprint in Turkish households. Environ Sci Pollut Res 27: 25009-25028

Czepkiewicz M, Heinonen J, Ottelin J (2018a) Why do urbanites travel more than do others? A review of associations between urban form and long-distance leisure travel. Environ Res Lett 13(7):073001

Czepkiewicz M, Ottelin J, Ala-Mantila S, Heinonen J, Hasanzadeh K, Kyttä M (2018b) Urban structural and socioeconomic effects on local, national and international travel patterns and greenhouse gas emissions of young adults. J Transp Geogr 68:130-141

Czepkiewicz M, Árnadóttir Á, Heinonen J (2019) Flights dominate travel emissions of Young urbanites. Sustainability 11(22):6340

Czepkiewicz M, Heinonen J, Næss P, Stefansdóttir H (2020) Who travels more, and why? A mixed-method study of urban dwellers' leisure travel. Travel Behav Soc 19:67-81

Dällenbach N (2020) Low-carbon travel mode choices: the role of time perceptions and familiarity. Transp Res Part D: Transp Environ 86: 102378
Dargay JM, Clark S (2012) The determinants of long distance travel in Great Britain. Transp Res A Policy Pract 46(3):576-587

Efthymiou M, Papatheodorou A (2019) EU emissions trading scheme in aviation: policy analysis and suggestions. J Clean Prod 237:117734

European Commission (2016) Flash Eurobarometer 432: Preferences of Europeans towards tourism, Brussels. https://data.europa.eu/euodp/ en/data/dataset/S2065 432 ENG

Filimonau V, Mika M, Pawlusiński R (2018) Public attitudes to biofuel use in aviation: evidence from an emerging tourist market. J Clean Prod 172:3102-3110

Gössling S (2019) Celebrities, air travel, and social norms. Ann Tour Res 79:102775

Gössling S, Humpe A (2020) The global scale, distribution and growth of aviation: implications for climate change. Glob Environ Chang 65: 102194

Gössling S, Upham P (2009) Climate change and aviation: issues, challenges and solutions. Earthscan

Gössling S, Ceron J-P, Dubois G, Hall CM (2009) Hypermobile travellers. In: Upham P (ed) Gössling, S. Climate change and aviation, Earthscan, pp 131-149

Gössling S, Lohmann M, Grimm B, Scott D (2017) Leisure travel distribution patterns of Germans: insights for climate policy. Case Studies on Transport Policy 5(4):596-603

Gössling S, Hanna P, Higham J, Cohen S, Hopkins D (2019) Can we fly less? Evaluating the 'necessity' of air travel. J Air Transp Manag 81: 101722

Gössling S, Humpe A, Bausch T (2020) Does 'flight shame'affect social norms? Changing perspectives on the desirability of air travel in Germany. Journal of Cleaner Production 122015

Graham A, Metz D (2017) Limits to air travel growth: the case of infrequent flyers. J Air Transp Manag 62:109-120

Graver B, Zhang K, Rutherford D (2019) Emissions from commercial aviation, 2018. Working paper 2019-16. International Council of Clean Transportation, 2

Heinonen J, Jalas M, Juntunen JK, Ala-Mantila S, Junnila S (2013) Situated lifestyles: I. How lifestyles change along with the level of urbanization and what the greenhouse gas implications are - a study of Finland. Environmental Research Letters 8(2):025003

Higham J, Cohen SA, Cavaliere CT, Reis A, Finkler W (2016) Climate change, tourist air travel and radical emissions reduction. J Clean Prod 111:336-347

Holden E, Norland I (2005) Three challenges for the compact city as a sustainable urban form: household consumption of energy and transport in eight residential areas in the greater Oslo region. Urban Stud 42:2145-2163

ICAO (2009) Global aviation CO2 emissions projections to 2050. Fourth Meeting of the Group on International Aviation and Climate Change, International Civil Aviation Organization, Montréal, Quebec, Canada

Lee DS, Fahey DW, Forster PM, Newton PJ, Wit RCN, Lim LL, Owen B, Sausen R (2009) Aviation and global climate change in the 21st century. Atmos Environ 43(22-23):3520-3537

Lenzen M, Sun YY, Faturay F, Ting YP, Geschke A, Malik A (2018) The carbon footprint of global tourism. Nat Clim Chang 8(6):522-528

Lu C (2018) When will biofuels be economically feasible for commercial flights? Considering the difference between environmental benefits and fuel purchase costs. J Clean Prod 181:365-373

O'Connell JF, Williams G (2005) Passengers' perceptions of low cost airlines and full service carriers: a case study involving Ryanair, Aer Lingus, Air Asia and Malaysia Airlines. J Air Transp Manag 11(4): 259-272

Qu J, Qin S, Liu L, Zeng J, Bian Y (2016) A hybrid study of multiple contributors to per capita household CO 2 emissions (HCEs) in China. Environ Sci Pollut Res 23(7):6430-6442 
Reichert A, Holz-Rau C, Scheiner J (2016) GHG emissions in daily travel and long-distance travel in Germany-social and spatial correlates. Transp Res Part D: Transp Environ 49:25-43

Reichert A, Holz-Rau C, Scheiner J (2018) Corrigendum to "GHG emissions in daily travel and long-distance travel in Germany-social and spatial correlates"[Transp. Res. D 49 (2016) 25-43]. Transp Res Part D: Transp Environ 65:854-857

Santos Silva JS, Tenreyro S (2006) The log of gravity. Rev Econ Stat 88(4):641-658

Schubert I, Sohre A, Ströbel M (2020) The role of lifestyle, quality of life preferences and geographical context in personal air travel. J Sustain Tour 28(10):1519-1550

Seetaram N, Song H, Ye S, Page S (2018) Estimating willingness to pay air passenger duty. Ann Tour Res 72:85-97
Shaari NF, Abdul-Rahim AS, Afandi SHM (2020) Are Malaysian airline passengers willing to pay to offset carbon emissions? Environ Sci Pollut Res 27:24242-24252

Statistics Austria (2017) Reisegewohnheiten der österreichischen Bevölkerung Quartale Stichprobenerhebungen zum Tages- und Nächtigungsreiseverkehr im In- und ins Ausland. StandardDokumentation Metainformationen. http://www.statistik.at/web_ de/statistiken/wirtschaft/tourismus/reisegewohnheiten/index.html

Tsui KWH (2017) Does a low-cost carrier lead the domestic tourism demand and growth of New Zealand? Tour Manag 60:390-403

Young M, Higham JE, Reis AC (2014) 'Up in the air': a conceptual critique of flying addiction. Ann Tour Res 49:51-64

Publisher's note Springer Nature remains neutral with regard to jurisdictional claims in published maps and institutional affiliations. 